Reprinted from The American Jodrnal of Hygient, Vol. IX, No. 2, 500-504, March, 1929.

\title{
EXPERIMENTS WITH NICOTINE UPON GROWING WHITE MICE.*
}

$\mathrm{BY}$

\section{H. THIENES.}

(Received for publication September 4, 1928.)

The possible influence of frequent absorption of nicotine over long periods of time upon growth, becomes an important question, due to the common use of tobacco by the youth of both sexes in recent years. Hatcher and Crosby (1) have demonstrated that lactating mothers excrete nicotine in their milk following the smoking of cigarettes, thus adding a further possibility of influence of nicotine upon human development at the time of greatest growth increment. Viewpoints on this question by laymen and members of the medical profession are decided, yet conflicting, and are unsupported by experimental or statistical data.

In the preliminary study here reported, mice were chosen because of the rapid reproduction and developmen't. Experiments were planned primarily for observing the effect of nicotine upon growth, yet certain other observations, incidental to the experiment, have been recorded. While results on mice cannot be transferred directly to the human, the essentially negative results obtained with nicotine on the growth rate, as measured by weight increase, challenges our reconsideration of the problem.

\section{Method.}

Injections of nicotine base, dissolved in 0.85 per cent $\mathrm{NaCl}$ solution, were made twice daily into the loose areolar tissue between the scapulae of growing white mice. The absolute dose was increased once or twice a week, according to the indications as judged by the severity of symptoms produced, namely, excitation or convulsions. From time to time, animals were lost from overdose.

Each litter of mice was divided into 2 approximately equal groups, one group being used as test animals, the other as controls. The controls received injections of $\mathrm{NaCl}$ solution alone. Injections were as a rule started the 7th to 10 th day after birth, when the hair became long enough for marking with dyes. In one litter, nicotine was started the 4th day, in another, the 16th day.

* From the Department of Pharmacology, University of Oregon, Portland. 
Since the sex of these very young mice could not be determined, there was no attempt to separate them into sex groups at the beginning of an experiment, but sex in most instances was determined later. Sex has little relation to growth for the first eight or ten weeks (2), so that this was not considered important at the time. However, the later determination of sex showed that for the whole series, the division of sexes in the control and test groups was about equal.

A mixed diet was used, consisting of whole wheat flour, greens, milk, cod liver oil and raw chopped beef. All the animals were kept together in one large cage, so that no check was made upon the amount of food consumed. The mice were weighed at twice weekly intervals in the early stages of growth, and once a week thereafter.

In all, 6 litters, comprising 32 mice, are represented in the data of this report. Of these, 18 were controls and 14 test mice. The growth curves of the test animals and of the controls in each litter were averaged, and the averages plotted. These curves were in no important particular different from the curves shown in figure 1, which represent the averages for the whole series.

\section{Results.}

Symptoms. Non-fatal doses produced symptoms ranging from mild excitation, with running about the cage, to severe clonic and tetanic convulsions. Dyspnea, with gnashing of teeth, was a prominent symptom, as were also stiffening of the tail and weakness of the hind legs. Symptoms usually persisted for but 10 to 15 minutes, although depression, following severe convulsions occasionally lasted 30 to 60 minutes. Fatal doses produced two types of symptoms. When death occurred early (1-3 minutes), it was preceded by a characteristic group of symptoms. Following the preliminary running abou and clonic convulsions, the head and forelegs were drawn strongly down on the chest, with elbows extended. The hind legs were drawn up to the abdomen and finally strongly extended, with toes widespread, tail and back strongly extended, head strongly flexed and ears lying flat to the head. Relaxation began in the forelimbs and head; the hind limbs were the last to relax. The heart continued to beat for from 15 to 120 seconds after relaxation of the body. The especially characteristic movement of this group of symptoms was the flexion, then extension of the hind limbs, which was invariably followed by death.* With the second type of fatal symptoms, death

* This symptom complex is of value in toxicologic analysis. Mice of 3 to 10 days are best, the tissue extract being dropped into the mouth of the animal. was delayed several minutes to an hour and occurred after an apparent recovery from the early convulsions, a gradual depression and respiratory failure leading to fatal termination. The heart continued to beat for several seconds after respirations ceased.

Susceptibility. As the test mice grew, the nicotine dose was gradually stepped up, and it was noted that the dosage could be increased more rapidly than the growth rate would indjcate. Whether this was due to an acquired tolerance, or simply to an increased resistance to nicotine with age was not determined. Edmunds (3) reported that young animals were more susceptible to nicotine than older ones. The small amount of data I have supports the view of a

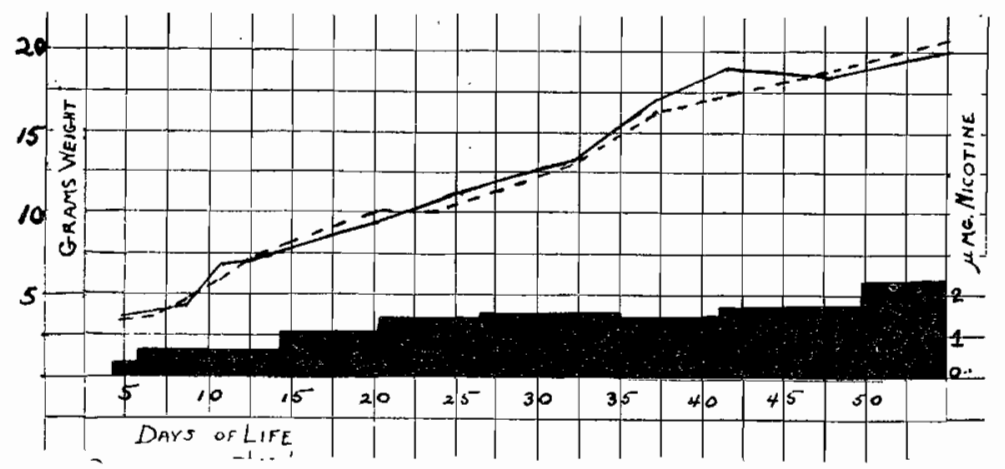

FIg. 1. Average growth rates of nicotine mice (broken line) and controls (solic line). Ordinates to the left express weight of mice in grams, abscissae the days of life, and ordinates to the right, the micromilligrams of nicotine per gram of meuso. The shaded area represents the increase of dose with age.

natural resistance with age, rather than an acquired tolerance. Both factors may readily take place. From time to time, animals were lost from overdose, resulting from what seemed to be a variation in susceptibility of individual mice, since a subconvulsive dose one day would occasionally kill a mouse the succeeding day. It is improbable that this was due to cumulative action, but may have resulted from variations in the rate of absorption. Table I gives the weekly changes in dose, averaged for all the litters and expressed as micromilligrams of nicotine per gram of mouse. The dosages are shown graphically as the shaded area in figure 1.

Growth. The failure of nicotine to affect growth is evidenced by the weight curves illustrated in figure 1 . The two curves are as nearly identical as could be expected from two small groups of animals; 
the deviations fall within the probable error, which was estimated to be between 5 and 10 per cent; data for the estimation were taken from Robertson's series (2) as well as from the present studies. This was an unlooked for result in view of the likelihood of impaired nutrition incident to alimentary disturbances resulting from excessive doses of nicotine. No outward evidence of gastro-intestinal disturbances was noted, however, and the appetite of the nicotine mice was apparently as good as that of the controls. The stools were of the same general appearance.

TABLE I.

The weekly change in dose, aneraged for all litters, expressed in micromilligrams of nicotine per gram of mouse.

\begin{tabular}{c|c|c|c|c|c|c|c|c}
\hline Week of life & 1 & 2 & 3 & 4 & 5 & 6 & 7 & 8 \\
\hline $\begin{array}{c}\text { Average dose of nicotine, in micromilli- } \\
\text { grams per gram of mouse............ }\end{array}$ & 0.3 & 0.8 & 1.1 & 1.5 & 1.6 & 1.5 & 1.7 & 2.3 \\
\hline
\end{tabular}

\section{Comment.}

It is not intended that the effects of injected nicotine be considered the same as those of smoking. Nevertheless, it is quite generally conceded that nicotine is chiefly responsible for the effects of tobacco smoking upon human subjects, so that experiments with nicotine are of prime importance for an understanding of the action of tobacco, in its entirety. Page (4) reported a slight early stimulation and later, retardation of growth of chicks given nicotine into the crop, but the difference between controls and test chicks was but little more than 10 per cent at any time so that he considered the difference too small to draw conclusions. Dixon and Lee (5), on the other hand, reported that young rabbits injected with nicotine grew to only half the size of the controls. They did not report the number of rabbits used, so that the statement is of little help in the solution of this problem. It is therefore desirable that further experiments on other species be made before general conclusions are drawn as to the effects of nicotine on growth.

\section{SUMmary.}

1. Nicotine was injected subcutaneously into 14 growing white mice twice daily, in doses sufficient to cause symptoms referable to the central nervous system; an equal volume of 0.85 per cent $\mathrm{NaCl}$ was injected into 18 controls. Symptoms due to the injections are described.
2. There developed a marked decrease in susceptibility to nicotine, as the nicotine mice grew older and larger. The cause of the decreased susceptibility was not determined.

3. Nicotine had no apparent effect upon growth, as judged by the weight-growth curves.

\section{Bibliography.}

1. Hatcher, R. A., ANd Crosby, Hilda.

1927. The elimination of nicotine in the milk. Jour. Pharm. Exp. Ther. 32, 1.

2. Robertson, T. BraILSFord.

1916. The normal growth of the white mouse. Jour. Biol. Chem. 24, 363. 3. Edmunds, C. W.

1909. Studies in tolerance. I. Nicotine and lobeline. Jour. Pharm. Exp. Ther. $1,27$.

4. Chase, Ralph E.

1928. The effect of nicotine and caffeine on the growth of chickens. The Amer. Jour. Physiol. 85, 527 .

5. Dixon, W. E., and Lee, W. E.

1912. Tolerance to nicotine. Quart. Jour. Exp. Physiol. 5, 373. 